\title{
The influence of addition of a catalyst and chelating agent on the properties of titanium dioxide synthesized via the sol-gel method
}

\author{
Katarzyna Siwińska-Stefańska ${ }^{1} \cdot$ Jakub Zdarta $^{1} \cdot$ Dominik Paukszta $^{1}$ • \\ Teofil Jesionowski ${ }^{1}$
}

Received: 15 July 2014/ Accepted: 27 March 2015/Published online: 9 April 2015

(c) The Author(s) 2015. This article is published with open access at Springerlink.com

\begin{abstract}
Titanium dioxide powders were prepared via the sol-gel method, using titanium alkoxide as a precursor. It was investigated how the addition of a catalyst (ammonia) and chelating agent (acetylacetone), as well as the temperature of calcination, affects the properties of the resulting $\mathrm{TiO}_{2}$ powder. The physicochemical properties of samples were determined, including the dispersion, morphology and microstructure of the systems (particle size distribution, TEM images), crystalline structure (XRD), characteristics of porous structure (BET), and thermal stability (TGA/DTA). The samples were also analyzed
\end{abstract}

using Fourier transform infrared spectroscopy. In addition, for selected $\mathrm{TiO}_{2}$ systems, their photocatalytic activity in the decomposition of C.I. Basic Blue 9 was investigated. Our research results show that the presence of chelating agent in the synthesis of titanium dioxide caused significant changes in dispersive properties, crystalline structure and porous structure parameters. The novel feature of this work is the proposed method of synthesis of highly photoactive titanium dioxide with desirable physicochemical properties in the presence of a chelating agent such as acetylacetone. Graphical Abstract

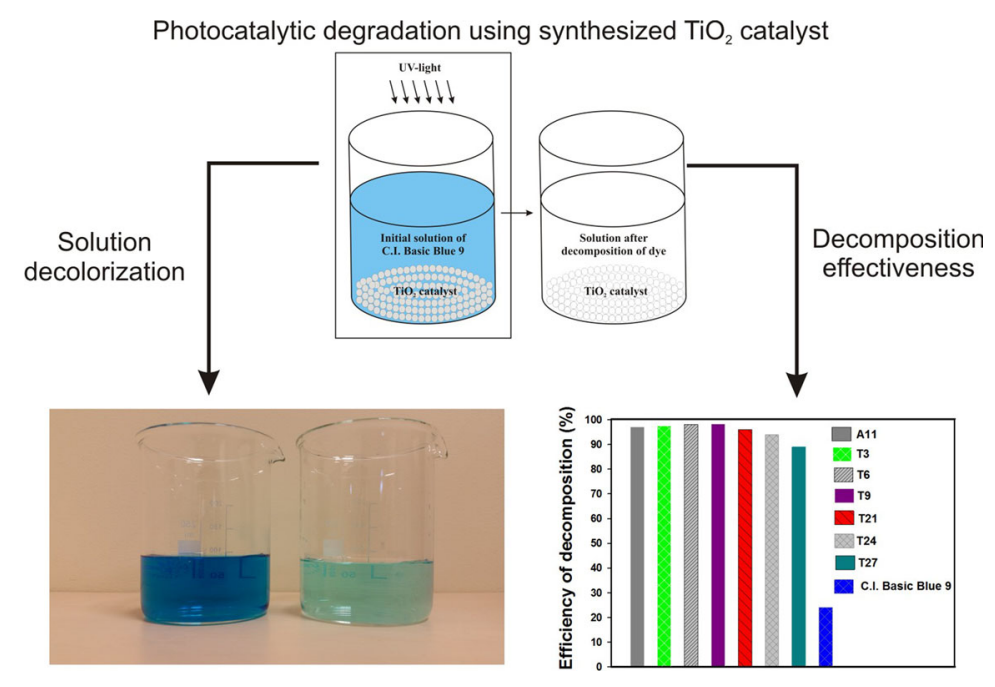

Katarzyna Siwińska-Stefańska

katarzyna.siwinska-stefanska@ put.poznan.pl

1 Faculty of Chemical Technology, Institute of Chemical

Technology and Engineering, Poznan University of Technology, Berdychowo 4, 60965 Poznan, Poland
Keywords Titania - Sol-gel method Chelating agent · Photocatalytic activity 


\section{Introduction}

The synthesis of titanium dioxide is one of the major research areas in 'green chemistry.' Titania is a chemically inert, thermally stable, insoluble, biocompatible, non-toxic material and an excellent absorber of destructive UV radiation. Because of these properties, titanium dioxide has for some time enjoyed a great and still growing popularity in many applications [1-3]. Titania-based photocatalytic systems are used for a variety of applications, such as decomposition of unwanted and toxic organic compounds, degradation of pollutants from contaminated water and air and destruction of harmful bacteria and cancer cells [4-9]. The properties of $\mathrm{TiO}_{2}$ are determined by the morphology of its particles, the size of its crystals and its crystalline structure, which depend on the choice of method for its synthesis and final heat treatment [10]. Nanocrystalline $\mathrm{TiO}_{2}$ particles are usually obtained by crystallization (chemical precipitation) [11], the microemulsion method (reverse micelles) [12], the sol-gel method [13-17] or hydrothermal crystallization [18-22]. Each of these methods has its own advantages and drawbacks, but a common factor that connects them is the ability to obtain materials with strictly defined properties.

The sol-gel method is a very flexible route for the synthesis of advanced materials in a wide variety of forms, such as spherical or ultrafine shaped powders, fibers, thin film coatings, dense or porous materials including highpurity inorganic oxides and hybrid (inorganic-organic) materials [23-27]. The sol-gel process is a useful synthetic method for the preparation of amorphous, as well as structurally ordered, materials. It offers advantages such as the possibility of obtaining homogeneous hybrid materials at low temperature, thereby enabling the incorporation of a variety of compounds [28-34]. A typical sol-gel method is based on hydrolysis and condensation of the precursor (inorganic metal salts or metal organic compounds such as metal alkoxides) [24]. This process can be employed for the synthesis of functionalized inorganic oxides with controlled particle size and shape [35-42]. In the sol-gel method, control of the reactivity of the metal alkoxides used as precursors is very important in order to obtain sols and gels with desirable properties. In sol-gel processing, for better control of the hydrolysis and condensation process, many different modifiers of alkoxide precursors can be used, including acetylacetone [43-45], acetic acid [43, 46] and other complex ligands.

The aim of this work is to study the correlation between the photocatalytic activity of $\mathrm{TiO}_{2}$ powders and various of its properties, including crystalline structure, surface area and particle size. It was investigated how certain conditions of preparation (addition of catalyst and chelating agent, and temperature of calcination) affect the microstructural evolution, porous structure parameters and photocatalytic capability of the resulting $\mathrm{TiO}_{2}$ powders. To examine the photocatalytic activity of the synthesized titanium dioxide, photodecomposition of C.I. Basic Blue 9 was carried out.

\section{Experimental}

\subsection{Materials}

Titanium dioxide powders were synthesized employing the sol-gel method, in which titanium tetraisopropoxide [Ti $\left(\mathrm{OC}_{3} \mathrm{H}_{7}\right)_{4}$-TTIP, $97 \%$, Sigma-Aldrich] was used as the precursor of titania, ammonia aqueous $\left(\mathrm{NH}_{3} \cdot \mathrm{H}_{2} \mathrm{O}\right.$, $25 \%$, Chempur $)$ as a catalyst, propan-2-ol $\left(\mathrm{C}_{3} \mathrm{H}_{7} \mathrm{OH}-\right.$ IPA, $99.5 \%$, Chempur) as the solvent and acetylacetone $\left(\mathrm{C}_{5} \mathrm{H}_{8} \mathrm{O}_{2}\right.$-AcAc, $99 \%$, Sigma-Aldrich) as a chelating agent. All reagents were used without any further purification.

\subsection{Synthesis of $\mathrm{TiO}_{2}$ via the sol-gel method}

Titanium dioxide powders were prepared via a sol-gel process, in which titania sol was prepared by mixing titanium tetraisopropoxide, propan-2-ol and ammonia, with or without chelating agent, at room temperature. In the first approach, $\mathrm{TiO}_{2}$ sol was prepared without the modifier (AcAc); TTIP as the starting material was introduced at a constant rate of $1 \mathrm{~mL} / \mathrm{min}$ using an ISM833A peristaltic pump (Ismatec) into a conical flask filled with a solution prepared by adding an appropriate amount of ammonia to IPA. The initially clear solution turned into a white dispersion. This solution was vigorously stirred for $1 \mathrm{~h}$ using a high-speed stirrer T25 basic type (IKA Werke GmbH), working at $800 \mathrm{rpm}$. The entire system was transferred to a round-bottomed flask and placed in a vacuum rotary evaporator (Rotavapor RII, Büchi Labortechnik GmbH), in order to remove the solvent IPA (water bath temperature $60{ }^{\circ} \mathrm{C}$, pressure $136 \mathrm{mbar}$ ). The next stage involved filtration of the mixture under reduced pressure. The sample obtained in this way was washed with distilled water to eliminate IPA. At the final stage, the sample was dried by convection at $105{ }^{\circ} \mathrm{C}$ for $18 \mathrm{~h}$ (SEL-I3 chamber drier, Memmert). The resulting samples were then calcined at 600,700 or $800{ }^{\circ} \mathrm{C}$ for $2 \mathrm{~h}$ (Nabertherm type Controller P320).

In the second approach, the $\mathrm{TiO}_{2}$ sol was prepared in the presence of acetylacetone. First, an appropriate amount of acetylacetone was mixed with TTIP using an IKAMAG R05 magnetic stirrer (IKA Werke $\mathrm{GmbH}$ ) for $40 \mathrm{~min}$. In the sol-gel method, AcAc was used as a stabilizing agent to control the rate of hydrolysis and condensation of the metal alkoxide. Acetylacetone has a reactive hydroxyl 
<smiles>CC(=O)CC(C)=O</smiles><smiles>CC1=COCC(C)=C1</smiles><smiles>CC(C)O</smiles>

$+$<smiles>CC(C)O[I-](I)(OC(C)C)OC(C)C</smiles><smiles></smiles>

Fig. 1 Interaction of acetylacetone with TTIP

group which reacts easily with the metal alkoxide and causes the transfer of an acidic proton from the acetylacetone to an alkoxy ligand, resulting in the corresponding alcohol and a modified alkoxide precursor, as presented in Fig. $1[45,47]$.

The reaction of metal alkoxide with AcAc is exothermic and produces a yellow solution, whereas both precursors were colorless liquids. The resulting precursor was then introduced at a constant rate of $1 \mathrm{~mL} / \mathrm{min}$, using an ISM833A peristaltic pump (Ismatec), into the solution prepared by adding an appropriate amount of ammonia to IPA. The products were analyzed in the same way as in the case of the preparation of pure titanium dioxide.

\subsection{Determination of physicochemical properties}

To determine the effect of the addition of the catalyst and chelating agent, and of the temperature of calcination, on the product's physicochemical properties, the obtained $\mathrm{TiO}_{2}$ samples were comprehensively analyzed using the most advanced analytical methods and techniques.

A Zetasizer Nano ZS (Malvern Instruments Ltd.) was used to determine the particle size distributions in the range 0.6-6000 nm, based on the noninvasive backscattering technique (NIBS). Each sample was prepared by dispersing $0.01 \mathrm{~g}$ of the tested product in $25 \mathrm{~mL}$ of propan-2-ol. The system was stabilized in an ultrasonic bath for $15 \mathrm{~min}$, and it was then placed in a cuvette and analyzed.
The morphology and microstructure of the $\mathrm{TiO}_{2}$ powders obtained was analyzed using a Jeol 1200 EX II transmission electron microscope, at an accelerating voltage of $100 \mathrm{kV}$. Microscopic photographs were taken using a direct reflection method, which involves covering a net with the firmware foil and then with a thin layer of carbon. On the surface prepared in this way, powder from the suspension was introduced. All samples of the prepared systems were tested in analogous electron conditions with appropriate magnification.

$\mathrm{X}$-ray diffraction (XRD) analysis was employed to determine the crystalline structure of the $\mathrm{TiO}_{2}$ materials. The measurements were performed using a TUR-M62 diffractometer, operating at $30 \mathrm{kV}$ and $25 \mathrm{~mA}$, with $\mathrm{CuK} \alpha(\alpha=1.5418 \AA)$ radiation, Ni filtered. The XRD pattern data were collected in step-scanning mode with steps of $\Delta 2 \theta=0.04^{\circ}$. Based on the $\mathrm{XRD}$ analysis results, it was possible to calculate crystallites size as well as to evaluate the relative content of rutile and anatase phases in prepared samples. Scherrer's equation [48], (101) and (110) reflections of anatase and rutile planes, respectively, were used for this purpose.

An ASAP 2020 porosimetry analyzer (Micromeritics Instrument Co.) was used to determine the porous structure parameters of the $\mathrm{TiO}_{2}$ materials, including BrunauerEmmett-Teller (BET) surface area, pore size and distribution in the mesoporous range, using low-temperature $\mathrm{N}_{2}$ sorption. The samples were first degassed for $4 \mathrm{~h}$ at $120^{\circ} \mathrm{C}$.

The thermal stability of the obtained $\mathrm{TiO}_{2}$ samples was determined by thermogravimetric analysis (TGA/DTA) (Jupiter STA 449 F3, Netzsch). Measurements were carried out under flowing nitrogen at a heating rate of $10{ }^{\circ} \mathrm{C} / \mathrm{min}$ and in a temperature range of $30-1000{ }^{\circ} \mathrm{C}$, with an initial sample weight of approximately $5 \mathrm{mg}$.

To identify the characteristic groups present on the surface of the $\mathrm{TiO}_{2}$ systems, the samples were subjected to FT-IR analysis using an IFS 66v/s spectrophotometer (Bruker). The samples were studied in the form of $\mathrm{KBr}$ tablets, as $\mathrm{KBr}$ crystals are inactive in the IR range. The analysis was performed over a range of $4000-400 \mathrm{~cm}^{-1}$.

\subsection{Evaluation of photocatalytic activity}

The photocatalytic activity of selected samples was tested via photodegradation of the organic dye C.I. Basic Blue 9. In order to establish the adsorption/desorption equilibrium between the dye and the catalyst surface, an appropriate amount of a $\mathrm{TiO}_{2}$ sample (the catalyst, $0.04 \mathrm{~g}$ ) was dispersed in an aqueous solution of C.I. Basic Blue 9 with a concentration of $5 \mathrm{mg} / \mathrm{L}$ and stirred using an IKAMAG R05 magnetic stirrer (IKA Werke $\mathrm{GmbH}$ ) for $15 \mathrm{~min}$ in the dark. Next, the suspension was irradiated with UV light for 15 min (Fig. 2), utilizing Laboratory-UV-Reactor system 2 (Heraeus). The UV light source was a $150 \mathrm{~W} \mathrm{Hg}$ lamp at room temperature. The 


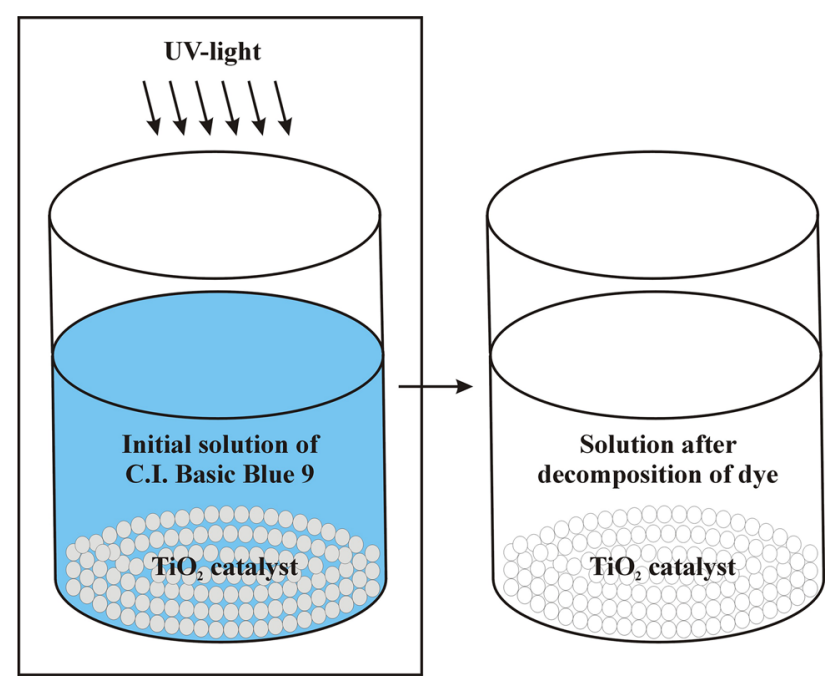

Fig. 2 Evaluation of photocatalytic activity of $\mathrm{TiO}_{2}$ catalyst

intermediate solutions were separated by filtration, and the concentration of C.I. Basic Blue 9 in aqueous solution (both after exposure and in the unexposed solution) was monitored by measuring light absorption at $661 \mathrm{~nm}$ with a SPEKOL UV1201 spectrometer (Shimadzu), using water as reference. The spectra obtained made it possible to evaluate the concentration of decomposed dye using the Lambert-Beer law (1):

$c_{t}=\frac{A}{(\varepsilon \times l)}$

where $c_{t}$ is the concentration of the dye after irradiation; A is the absorbance; $\varepsilon$ is the molar absorption coefficient, $\varepsilon_{\max }=66,700 \mathrm{~L} / \mathrm{mol} \cdot \mathrm{cm}$ at a wavelength of $\lambda=661 \mathrm{~nm}$ for C.I. Basic Blue 9; and 1 is the thickness of the absorbing layer (on the path of the radiation passing through the cuvette solution, $l=1 \mathrm{~cm}$ ).

The photocatalytic activity of titanium dioxide in the photodegradation of the organic dye was determined by calculating the yield of dye degradation $(W)$, using the formula (2):

$W(\%)=\left(1-\frac{c_{t}}{c_{0}}\right) \times 100 \%$

where $c_{0}$ is the concentration of the substrate prior to irradiation and $c_{t}$ is the concentration of the substrate after irradiation.

\section{Results}

\subsection{Dispersive and microstructural properties of $\mathrm{TiO}_{2}$}

The aim of the first stage of the study was to determine the dispersive and microstructural properties of the inorganic, synthetic $\mathrm{TiO}_{2}$ obtained via the sol-gel method with different molar ratios of catalyst (ammonia).

The results of the dispersive analysis (Table 1) show that both the addition of a catalyst and the conditions of the thermal process have a significant effect on the dispersion of the resulting materials. The data show that, irrespective of the temperature of calcination, samples with the most favorable dispersion were obtained at the molar ratio TTIP/ $\mathrm{NH}_{3} \cdot \mathrm{H}_{2} \mathrm{O}=1.48$. All of the products have monomodal particle size distributions. Samples T1, T4 and T7, obtained using the molar ratio TTIP/NH $/ \mathrm{N}_{3} \cdot \mathrm{H}_{2} \mathrm{O}=1.48$ and calcined, respectively, at $600{ }^{\circ} \mathrm{C}, 700{ }^{\circ} \mathrm{C}$ and $800{ }^{\circ} \mathrm{C}$, contain particles in the ranges $122-615,220-712$ and 396-1110 nm. These bands correspond to the presence of primary particles and agglomerates. These samples also exhibit high homogeneity, as is shown by the low values of the polydispersity index (respectively, 0.256, 0.113 and 0.187 ). It was also observed for all of the analyzed materials that, with an increase in the quantity of ammonia used as a catalyst in the process of obtaining $\mathrm{TiO}_{2}$ by the sol-gel method, there is an increase in the particle diameters of the various systems. It can be assumed that an increase in the quantity of catalyst used in the sol-gel process leads to an increase in the degree of nucleation and hydrolysis, resulting in particles of larger diameter and with a significant tendency to agglomerate. The results of the dispersive analysis also showed that the calcination temperature significantly affects the dispersion of the resulting titanium dioxide. As the heat processing temperature increases, the particle diameters are found to shift toward higher values, this being an effect of the sintering and greater agglomeration of the particles (Table 1).

The TEM microphotographs of selected titanium dioxide samples (samples T1, T4 and T7, obtained at the molar ratio TTIP/ $/ \mathrm{NH}_{3} \cdot \mathrm{H}_{2} \mathrm{O}=1.48$ and calcined at temperatures of $600{ }^{\circ} \mathrm{C}, 700{ }^{\circ} \mathrm{C}$ and $800{ }^{\circ} \mathrm{C}$, respectively) are presented in Fig. 3.

TEM images of samples obtained (Fig. 3) inform about their inhomogeneous structure and the presence of primary particles and secondary agglomerates. Particles of irregular shapes make larger clusters. The TEM microphotographs of the studied samples confirm the presence of particles of precisely designed diameter (corresponding to those indicated in the particle size distributions).

At the next stage, it was investigated how the addition of chelating agent affects the dispersion and microstructure of titanium dioxide obtained by the sol-gel method. It was first determined how the addition of acetylacetone affects the dispersive properties of samples additionally calcined at $600{ }^{\circ} \mathrm{C}$. Dispersive analysis of these samples of $\mathrm{TiO}_{2}$ (Table 2) showed that the addition of AcAc leads to products with smaller particle diameter values. The most favorable dispersion was observed in samples obtained 
with the addition of chelating agent in a quantity of $0.0096 \mathrm{~mol}$, irrespective of the quantity of ammonia used as catalyst (samples T19, T20 and T21). The analyzed samples have monomodal particle size distributions, in the ranges 164-396 nm (sample T19) and 164-459 nm (samples T20 and T21). The addition of chelating agent leads not only to products characterized by the presence of particles of smaller diameter, but also a visible shift in the diameter of the particles with the maximum volume contribution toward smaller diameter values. Among the analyzed samples, the maximum volume contribution comes from particles of diameter $255 \mathrm{~nm}$ (samples T19 and T21) and $295 \mathrm{~nm}$ (sample T20). However, analysis of the values of the polydispersity index shows that the addition of a stabilizer in a quantity of 0.0096 mol leads to a product which is less homogeneous than a sample obtained without the addition of AcAc.

Table 2 also shows the dispersive properties of samples of titanium dioxide obtained with or without the addition of stabilizer, calcined at 700 and $800{ }^{\circ} \mathrm{C}$, respectively. Dispersive analysis of the samples obtained with the addition of acetylacetone shows that the proposed method of synthesis leads to a product in which particles with smaller diameter values are present. In most cases, it also leads to products with poorer homogeneity. The samples with the most favorable dispersion were obtained by adding chelating agent in a quantity of 0.0096 mol (samples T22$\mathrm{T} 24$ and T25-T27, calcined at 700 and $800{ }^{\circ} \mathrm{C}$, respectively). In summary, it was confirmed that the addition of a stabilizer causes a shift in particle diameters toward lower values, irrespective of the further thermal processing of the $\mathrm{TiO}_{2}$. Our observations are in agreement with previous research [44]. The results of dispersive analysis showed an apparent downward trend in the particle diameter as the quantity of AcAc decreases. It is well known that the presence of chelating agent in the synthesis of titanium dioxide decreases the rate of hydrolysis and results in the formation of particles of smaller diameter [46].

Figure 4 shows TEM microphotographs of selected samples (T19, T22 and T25) obtained with the addition of chelating agent in an amount of $0.0096 \mathrm{~mol}$ and calcined at different temperatures, which confirm the presence of particles of nanosized diameters (corresponding to those in the indicated particle size ranges). The particles are almost spherical in shape and show only a slight tendency to form agglomerate structures. The TEM images of $\mathrm{TiO}_{2}$ particles prepared with AcAc addition show spherical particles and narrow size distribution. $\mathrm{TiO}_{2}$ particles obtained without chelating ligand (Fig. 3) are highly agglomerated, and most of them are non-spherical. Those differences in morphology and particle sizes indicate that the addition of the nucleophilic ligand in preparation of $\mathrm{TiO}_{2}$ samples leads to fine powders containing homogeneous as well as spherical particles.

\subsection{Structural characteristic of synthetic titanium dioxide}

XRD patterns of $\mathrm{TiO}_{2}$ samples calcined at different temperature $\left(600,700\right.$ and $\left.800{ }^{\circ} \mathrm{C}\right)$ are shown in Fig. 5. XRD measurement of titanium dioxide calcined at $600{ }^{\circ} \mathrm{C}$ (the sample labeled as T3) shows a strong peak occurring at $2 \theta=25.3^{\circ}$, which corresponds to the (101) reflection, while other characteristic peaks-(004), (200), (105) and (211) - correspond to different crystalline planes. These peaks confirm the presence of the polycrystalline anatase structure of $\mathrm{TiO}_{2}$. The rutile $\mathrm{TiO}_{2}$ phase is not observed in this sample. The XRD patterns of titanium dioxide powders calcined at higher temperatures $\left(700\right.$ and $800{ }^{\circ} \mathrm{C}$ - samples

Table 1 Dispersive properties of titanium dioxide powders obtained at different amount of catalyst

\begin{tabular}{|c|c|c|c|c|c|c|}
\hline \multirow[t]{2}{*}{ Sample } & \multicolumn{3}{|c|}{ Amount of reactants (mol) } & \multirow{2}{*}{$\begin{array}{l}\text { Particle size } \\
\text { distributions } \\
\text { by volume }(\mathrm{nm})\end{array}$} & \multirow{2}{*}{$\begin{array}{l}\text { Maximum } \\
\text { volume } \\
\text { contribution (\%) }\end{array}$} & \multirow{2}{*}{$\begin{array}{l}\text { Polydispersity } \\
\text { index }\end{array}$} \\
\hline & IPA & TTIP & $\mathrm{NH}_{3} \cdot \mathrm{H}_{2} \mathrm{O}$ & & & \\
\hline \multicolumn{7}{|c|}{ Calcined at $600{ }^{\circ} \mathrm{C}$} \\
\hline $\mathrm{T} 1$ & 1.304 & 0.049 & 0.033 & $122-615$ & $164 \mathrm{~nm}-14.4$ & 0.256 \\
\hline $\mathrm{T} 2$ & & & 0.049 & $255-1480$ & $459 \mathrm{~nm}-13.1$ & 0.359 \\
\hline $\mathrm{T} 3$ & & & 0.065 & $459-1480$ & $825 \mathrm{~nm}-24.2$ & 0.311 \\
\hline \multicolumn{7}{|c|}{ Calcined at $700{ }^{\circ} \mathrm{C}$} \\
\hline $\mathrm{T} 4$ & 1.304 & 0.049 & 0.033 & $220-712$ & $396 \mathrm{~nm}-23.8$ & 0.113 \\
\hline T5 & & & 0.049 & $255-955$ & $531 \mathrm{~nm}-21.6$ & 0.257 \\
\hline T6 & & & 0.065 & $459-1480$ & $825 \mathrm{~nm}-23.4$ & 0.159 \\
\hline \multicolumn{7}{|c|}{ Calcined at $800^{\circ} \mathrm{C}$} \\
\hline $\mathrm{T} 7$ & 1.304 & 0.049 & 0.033 & $396-1110$ & $712 \mathrm{~nm}-28.4$ & 0.187 \\
\hline $\mathrm{T} 8$ & & & 0.049 & $531-1480$ & $955 \mathrm{~nm}-27.7$ & 0.431 \\
\hline Т9 & & & 0.065 & $531-2300$ & $1480 \mathrm{~nm}-15.5$ & 0.321 \\
\hline
\end{tabular}


Fig. 3 TEM images of titanium dioxide powders: a T1, b T4 and $\mathbf{c ~ T 7}$

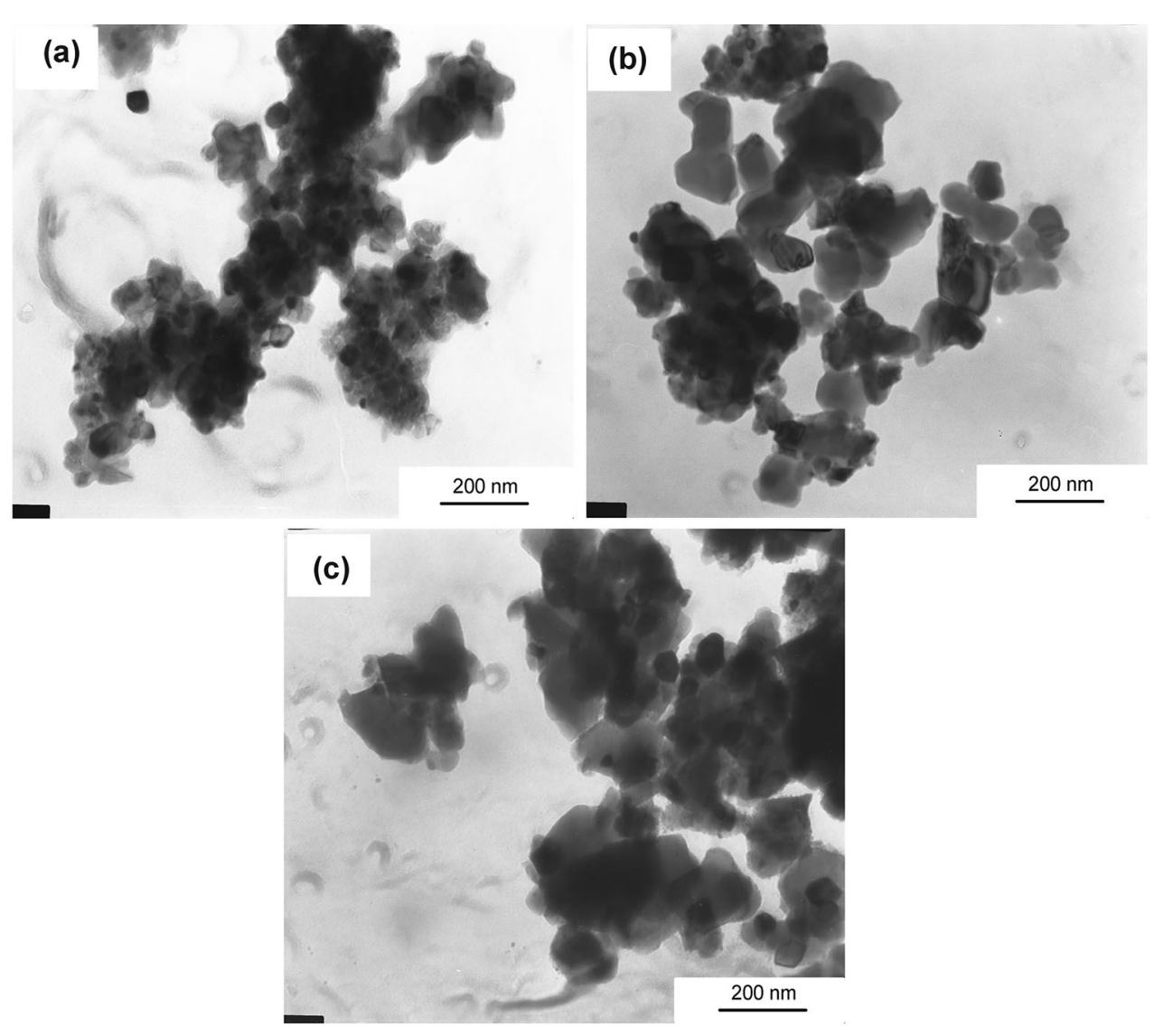

T6 and T9) were found also to be crystalline, but with diffraction peaks corresponding to both anatase and rutile forms. For both of these samples, there was a perceptible weakening in the intensity of the diffraction peaks (101), (004), (200) and (211) that correspond to the anatase form, while the characteristic peaks (110), (101), (200), (111), (210), (211) and (220) that correspond to the rutile structure were also observed. The formation of a rutile structure was observed in $\mathrm{TiO}_{2}$ samples calcined above $700{ }^{\circ} \mathrm{C}$ (samples T6 and T9). The calcination process is necessary to eliminate water and organic species arising from the initial reactants. Moreover, it was found that the temperature of calcination significantly affects the crystalline structure of the titanium dioxide. Calcination at $600{ }^{\circ} \mathrm{C}$ leads to a product with a pure anatase structure, whereas a higher calcination temperature leads to a product with a mixed rutile and anatase structure, in which rutile nonetheless dominates. The XRD analysis shows that the contribution of rutile structure increases with increasing temperature of calcination.

Table 3 presents crystallite sizes and relative percentage content of anatase and rutile in obtained titanium dioxide samples, additionally calcined at various temperatures. The average crystallite sizes of $\mathrm{TiO}_{2}$ samples were calculated using width of the XRD peak at $2 \theta=25.3^{\circ}$ and $27.5^{\circ}$ measure at its half-high utilizing the Scherrer equation. Sample T3, calcined at $600{ }^{\circ} \mathrm{C}$, contains only anatase phase with an average crystallite size of about $39 \mathrm{~nm}$. On the other hand, sample calcined at $700{ }^{\circ} \mathrm{C}-\mathrm{T} 6$-is composed of anatase crystallites of $47 \mathrm{~nm}$ and the transformed rutile phase that appears with crystallites size of about $39 \mathrm{~nm}$. Sample T9 (calcined at $700{ }^{\circ} \mathrm{C}$ ) contains both anatase and rutile phases with crystallites of $47 \mathrm{~nm}$ in size. The relative percentage content of anatase and rutile phases in obtained samples was calculated using equation given in the literature [49]. Sample T3 is composed only of anatase, and sample T6 contains 25 and $75 \%$ and sample T9 contains 11 and $89 \%$ of anatase and rutile, respectively. The crystallites size as well as the relative percentage content of rutile increases together with increasing temperature of calcination.

In the next stage of the physicochemical analysis, the effect of the addition of chelating agent (acetylacetone) on the crystalline structure of calcined titanium dioxide was examined (Fig. 6). Figure 6a shows diffractograms of samples of titanium dioxide obtained with the addition of various amounts of acetylacetone and calcined at $600{ }^{\circ} \mathrm{C}$. In the case of the samples obtained with the use of the chelating agent (samples T12 and T21), the XRD patterns show a weak peak occurring at $2 \theta=27.4^{\circ}$, which 
Table 2 Dispersive properties of titanium dioxide powders obtained at different amount of catalyst and chelating agent and calcined at different temperature

\begin{tabular}{|c|c|c|c|c|c|c|c|}
\hline \multirow[t]{2}{*}{ Sample } & \multicolumn{4}{|c|}{ Amount of reactants (mol) } & \multirow{2}{*}{$\begin{array}{l}\text { Particle size } \\
\text { distributions } \\
\text { by volume }(\mathrm{nm})\end{array}$} & \multirow{2}{*}{$\begin{array}{l}\text { Maximum } \\
\text { volume } \\
\text { contribution } \\
(\%)\end{array}$} & \multirow{2}{*}{$\begin{array}{l}\text { Polydispersity } \\
\text { index }\end{array}$} \\
\hline & IPA & TTIP & $\mathrm{NH}_{3} \cdot \mathrm{H}_{2} \mathrm{O}$ & $\mathrm{AcAc}$ & & & \\
\hline \multicolumn{8}{|c|}{ Calcined at $600{ }^{\circ} \mathrm{C}$} \\
\hline $\mathrm{T} 1$ & 1.304 & 0.049 & 0.033 & - & $122-615$ & $164 \mathrm{~nm}-14.4$ & 0.256 \\
\hline $\mathrm{T} 10$ & & & & 0.0193 & $255-615$ & $396 \mathrm{~nm}-29.7$ & 0.285 \\
\hline T19 & & & & 0.0096 & $164-396$ & $255 \mathrm{~nm}-34.3$ & 0.808 \\
\hline $\mathrm{T} 2$ & & & 0.049 & - & $255-1480$ & $459 \mathrm{~nm}-13.1$ & 0.359 \\
\hline T11 & & & & 0.0193 & $255-459$ & $342 \mathrm{~nm}-37.1$ & 0.742 \\
\hline $\mathrm{T} 20$ & & & & 0.0096 & $164-459$ & $295 \mathrm{~nm}-21.1$ & 0.190 \\
\hline $\mathrm{T} 3$ & & & 0.065 & - & $459-1480$ & $825 \mathrm{~nm}-24.2$ & 0.311 \\
\hline T12 & & & & 0.0193 & $220-712$ & $342 \mathrm{~nm}-24.7$ & 0.374 \\
\hline $\mathrm{T} 21$ & & & & 0.0096 & $164-459$ & $255 \mathrm{~nm}-26.5$ & 0.411 \\
\hline \multicolumn{8}{|c|}{ Calcined at $700{ }^{\circ} \mathrm{C}$} \\
\hline $\mathrm{T} 4$ & 1.304 & 0.049 & 0.033 & - & $220-712$ & $396 \mathrm{~nm}-23.8$ & 0.113 \\
\hline T13 & & & & 0.0193 & $122-255$ & $164 \mathrm{~nm}-30.4$ & 0.643 \\
\hline $\mathrm{T} 22$ & & & & 0.0096 & $106-255$ & $142 \mathrm{~nm}-39.1$ & 0.588 \\
\hline T5 & & & 0.049 & - & $255-955$ & $531 \mathrm{~nm}-21.6$ & 0.257 \\
\hline T14 & & & & 0.0193 & $255-712$ & $459 \mathrm{~nm}-31.4$ & 0.195 \\
\hline $\mathrm{T} 23$ & & & & 0.0096 & $122-396$ & $190 \mathrm{~nm}-24.0$ & 0.418 \\
\hline T6 & & & 0.065 & - & $459-1480$ & $825 \mathrm{~nm}-23.4$ & 0.159 \\
\hline $\mathrm{T} 15$ & & & & 0.0193 & $220-825$ & $459 \mathrm{~nm}-23.8$ & 0.141 \\
\hline $\mathrm{T} 24$ & & & & 0.0096 & $190-615$ & $295 \mathrm{~nm}-25.3$ & 0.524 \\
\hline \multicolumn{8}{|c|}{ Calcined at $800^{\circ} \mathrm{C}$} \\
\hline $\mathrm{T} 7$ & 1.304 & 0.049 & 0.033 & - & $396-1110$ & $712 \mathrm{~nm}-28.4$ & 0.187 \\
\hline T16 & & & & 0.0193 & $164-712$ & $190 \mathrm{~nm}-16.2$ & 0.921 \\
\hline $\mathrm{T} 25$ & & & & 0.0096 & $164-531$ & $295 \mathrm{~nm}-23.5$ & 0.173 \\
\hline $\mathrm{T} 8$ & & & 0.049 & - & $531-1480$ & $955 \mathrm{~nm}-27.7$ & 0.431 \\
\hline T17 & & & & 0.0193 & $255-1110$ & $531 \mathrm{~nm}-22.6$ & 0.145 \\
\hline $\mathrm{T} 26$ & & & & 0.0096 & $122-396$ & $190 \mathrm{~nm}-19.8$ & 0.589 \\
\hline T9 & & & 0.065 & - & $531-2300$ & $1480 \mathrm{~nm}-15.5$ & 0.321 \\
\hline T18 & & & & 0.0193 & $190-615$ & $342 \mathrm{~nm}-23.3$ & 0.392 \\
\hline $\mathrm{T} 27$ & & & & 0.0096 & $142-459$ & $220 \mathrm{~nm}-21.5$ & 0.217 \\
\hline
\end{tabular}

corresponds to the (110) reflection of the rutile structure, as compared to the sample obtained without AcAc (sample T3). Analysis of the data leads to the conclusion that the addition of acetylacetone at the stage of titanium dioxide synthesis, followed by calcination, leads to a mixed anatase and rutile structure, the former type being dominant. However, diffractograms obtained for the samples calcined at higher temperatures show a reduction or vanishing of the characteristic anatase diffraction bands (101), (004), (200)_-this applies to samples T15, T24 and T18, T27, calcined, respectively, at 700 and $800{ }^{\circ} \mathrm{C}$.

Preparation of $\mathrm{TiO}_{2}$ samples with the addition of AcAc caused significant changes in crystallites characteristic. Sample T12 (calcined at $600{ }^{\circ} \mathrm{C}$ ) contains both anatase and rutile phases with crystallite size of 47 and $39 \mathrm{~nm}$, respectively. It means that the presence of chelating agent in preparation process leads to decrease in temperature of transformation of anatase to rutile. Moreover, anatase phase is characterized with higher crystallite sizes as compared to the sample T3. The higher the temperature of calcination (700 and $800{ }^{\circ} \mathrm{C}$-samples T15, T24 and T18, T27, respectively), the increase in rutile phase content together with decrease in amount of anatase was observed. Samples prepared with the smallest addition of AcAc are characterized with the biggest crystallites of $59 \mathrm{~nm}$. Our observations are in agreement with Chang et al.'s studies [49].

Based on the results of XRD analysis, it was concluded that the preparation of titanium dioxide in the presence of a 
Fig. 4 TEM images of titanium dioxide obtained with the addition of AcAc: a T19, b T22 and $\mathbf{c}$ T25
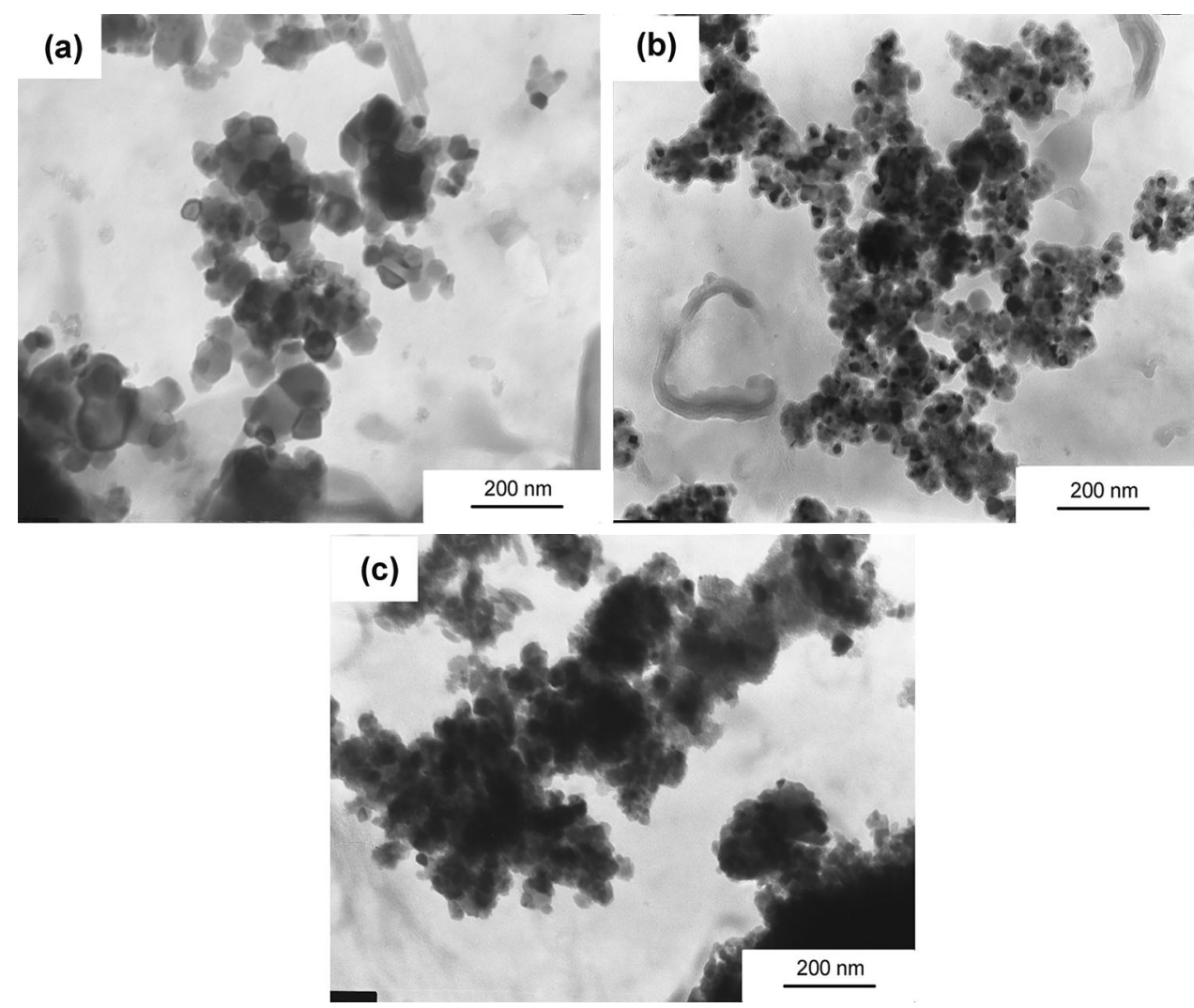

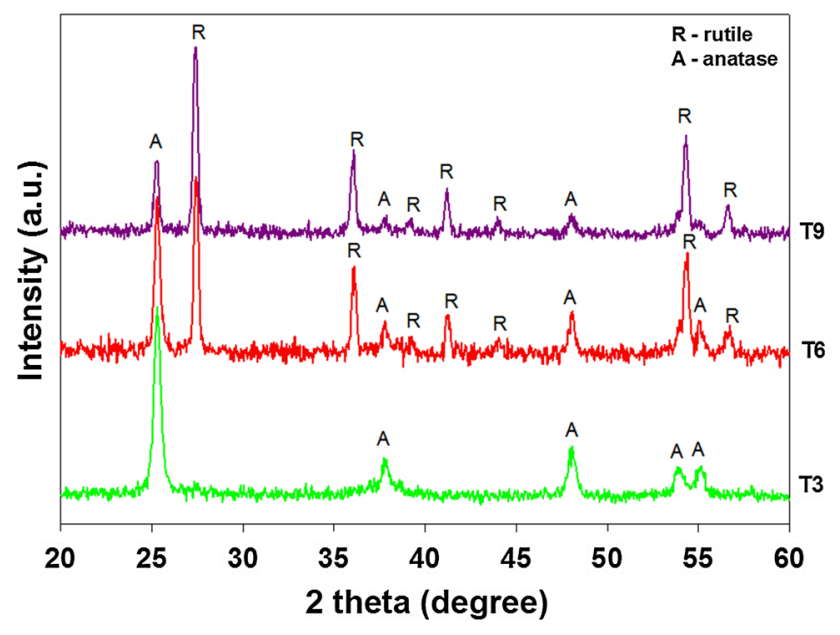

Fig. 5 XRD patterns of titanium dioxide calcined at 600, 700 and $800{ }^{\circ} \mathrm{C}$

chelating agent $(\mathrm{AcAc})$ influences the crystalline structure of the $\mathrm{TiO}_{2}$ and causes a decrease in the temperature of transformation of the anatase phase to rutile. With an increase in the quantity of the chelating agent introduced at the stage of synthesis of $\mathrm{TiO}_{2}$, there is observed a decrease in the intensity of the diffraction peaks characteristic of anatase $\left(2 \theta=25.3^{\circ}\right)$, irrespective of the temperature of thermal processing.

\subsection{Porous structure}

In order to investigate the structural properties of $\mathrm{TiO}_{2}$, selected samples were analyzed using a physisorption analyzer. Figures 7 and 8 show the fundamental parameters used to determine the structural properties of the samples obtained (BET surface area, total volume and mean size of pores).

The nitrogen isotherms recorded for obtained $\mathrm{TiO}_{2}$ samples indicate the non-porous or macroporous character of the materials (Fig. 7). Those isotherms were classified as type II with hysteresis loops type H3. Sample T3 (calcined at $600{ }^{\circ} \mathrm{C}$ ) is characterized with the highest surface area (BET) of $13.9 \mathrm{~m}^{2} / \mathrm{g}$.

At the next stage, the influence of chelating agent addition on the parameters of the porous structure of titanium dioxide obtained by the sol-gel method (Fig. 7b) was investigated. Analysis of the data presented in Fig. 7b shows that the smaller the amount of the chelating agent, the higher the surface area parameter. As compared to sample $\mathrm{T} 3$, the highest surface area of $15.7 \mathrm{~m}^{2} / \mathrm{g}$ was noted for T21 powder.

Analysis of the porous structure of titanium dioxide obtained with appropriate amounts of ammonia and calcined at different temperatures (Fig. 8) shows that sample T3 (calcined at $600{ }^{\circ} \mathrm{C}$ ) has the highest surface area $\left(13.9 \mathrm{~m}^{2} / \mathrm{g}\right)$, while its pore volume is $0.010 \mathrm{~cm}^{3} / \mathrm{g}$ and 
Table 3 Crystallites size and relative percentage content of anatase and rutile in titanium dioxide powders obtained at different amount of chelating agent and calcined at different temperature

\begin{tabular}{|c|c|c|c|c|c|c|c|c|}
\hline \multirow[t]{2}{*}{ Sample } & \multicolumn{4}{|c|}{ Amount of reactants (mol) } & \multicolumn{2}{|c|}{ Crystallite size $(\mathrm{nm})$} & \multicolumn{2}{|c|}{ Content $(\%)$} \\
\hline & IPA & TTIP & $\mathrm{NH}_{3} \cdot \mathrm{H}_{2} \mathrm{O}$ & $\mathrm{AcAc}$ & Anatase & Rutile & Anatase & Rutile \\
\hline \multicolumn{9}{|c|}{ Calcined at $600{ }^{\circ} \mathrm{C}$} \\
\hline $\mathrm{T} 3$ & 1.304 & 0.049 & 0.065 & - & 39 & - & 100 & - \\
\hline $\mathrm{T} 12$ & & & & 0.0193 & 47 & 39 & 95 & 5 \\
\hline $\mathrm{T} 21$ & & & & 0.0096 & 47 & 47 & 93 & 7 \\
\hline \multicolumn{9}{|c|}{ Calcined at $700{ }^{\circ} \mathrm{C}$} \\
\hline T6 & 1.304 & 0.049 & 0.065 & - & 39 & 39 & 25 & 75 \\
\hline $\mathrm{T} 15$ & & & & 0.0193 & 47 & 59 & 7 & 93 \\
\hline $\mathrm{T} 24$ & & & & 0.0096 & 59 & 59 & 13 & 87 \\
\hline \multicolumn{9}{|c|}{ Calcined at $800^{\circ} \mathrm{C}$} \\
\hline T9 & 1.304 & 0.049 & 0.065 & - & 47 & 47 & 11 & 89 \\
\hline $\mathrm{T} 18$ & & & & 0.0193 & 47 & 59 & 3 & 97 \\
\hline $\mathrm{T} 27$ & & & & 0.0096 & 59 & 59 & 3 & 97 \\
\hline
\end{tabular}

Fig. 6 XRD patterns of titanium dioxide obtained with AcAc addition and calcined at: a $600{ }^{\circ} \mathrm{C}$, b $700{ }^{\circ} \mathrm{C}$ and c $800^{\circ} \mathrm{C}$
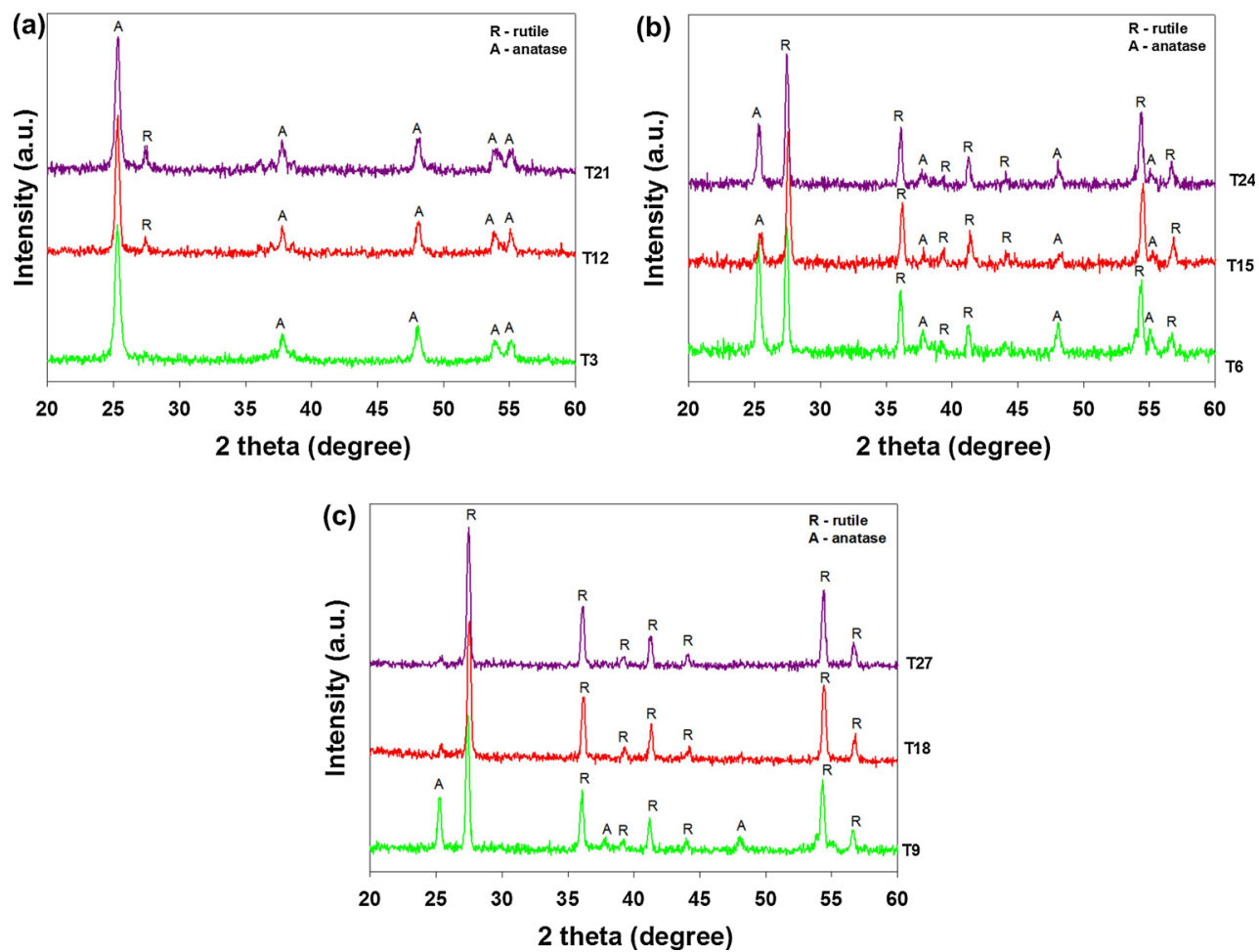

mean pore diameter $2.8 \mathrm{~nm}$. Sample T9 (calcined at $\left.800{ }^{\circ} \mathrm{C}\right)$ has the lowest surface area $\left(7.4 \mathrm{~m}^{2} / \mathrm{g}\right)$, its pore volume and mean pore diameter being $0.004 \mathrm{~cm}^{3} / \mathrm{g}$ and $4.5 \mathrm{~nm}$, respectively.

Based on analysis of the data for $\mathrm{TiO}_{2}$ samples obtained with the addition of acetylacetone in an amount of 0.0096 mol (samples T21, T24 and T27), it is found that these products have slightly higher values for the BET surface area than those of $\mathrm{TiO}_{2}$ obtained in the traditional manner. Sample T21 (calcined at $600{ }^{\circ} \mathrm{C}$ ) has a surface area of $15.7 \mathrm{~m}^{2} / \mathrm{g}$, a total pore volume of $0.011 \mathrm{~cm}^{3} / \mathrm{g}$ and a pore diameter of $2.9 \mathrm{~nm}$. In the case of sample T27 (calcined at $800{ }^{\circ} \mathrm{C}$ ), the total pore volume is $0.002 \mathrm{~cm}^{3} / \mathrm{g}$, the pore diameter $2.7 \mathrm{~nm}$ and the BET surface area $9.2 \mathrm{~m}^{2} / \mathrm{g}$. The addition of a chelating agent in the amount $0.0096 \mathrm{~mol}$ leads to an increase in the surface area and pore volume of the products, irrespective of the temperature of calcination. The values for pore diameter, however, were found to decrease. The increase in the BET surface area for the samples obtained using the chelating agent (AcAc) in an 

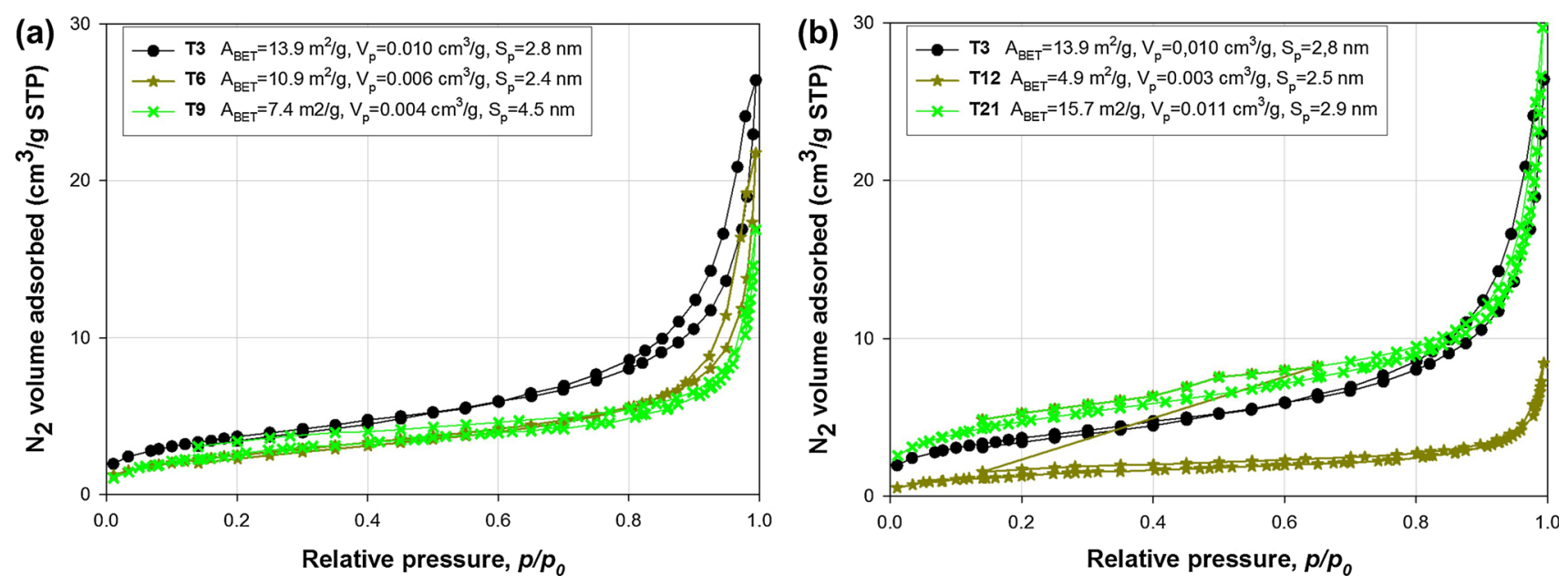

Fig. 7 Nitrogen adsorption/desorption isotherms for titanium dioxide obtained: a without chelating agent and calcined at different temperature and $\mathbf{b}$ with AcAc addition and calcined at $600{ }^{\circ} \mathrm{C}$

Fig. 8 Parameters of the porous structures of titanium dioxide obtained with or without calcined at different temperature: a BET surface area, $\mathbf{b}$ pore volume and, $\mathbf{c}$ pore size versus AcAc amount addition of chelating agent and
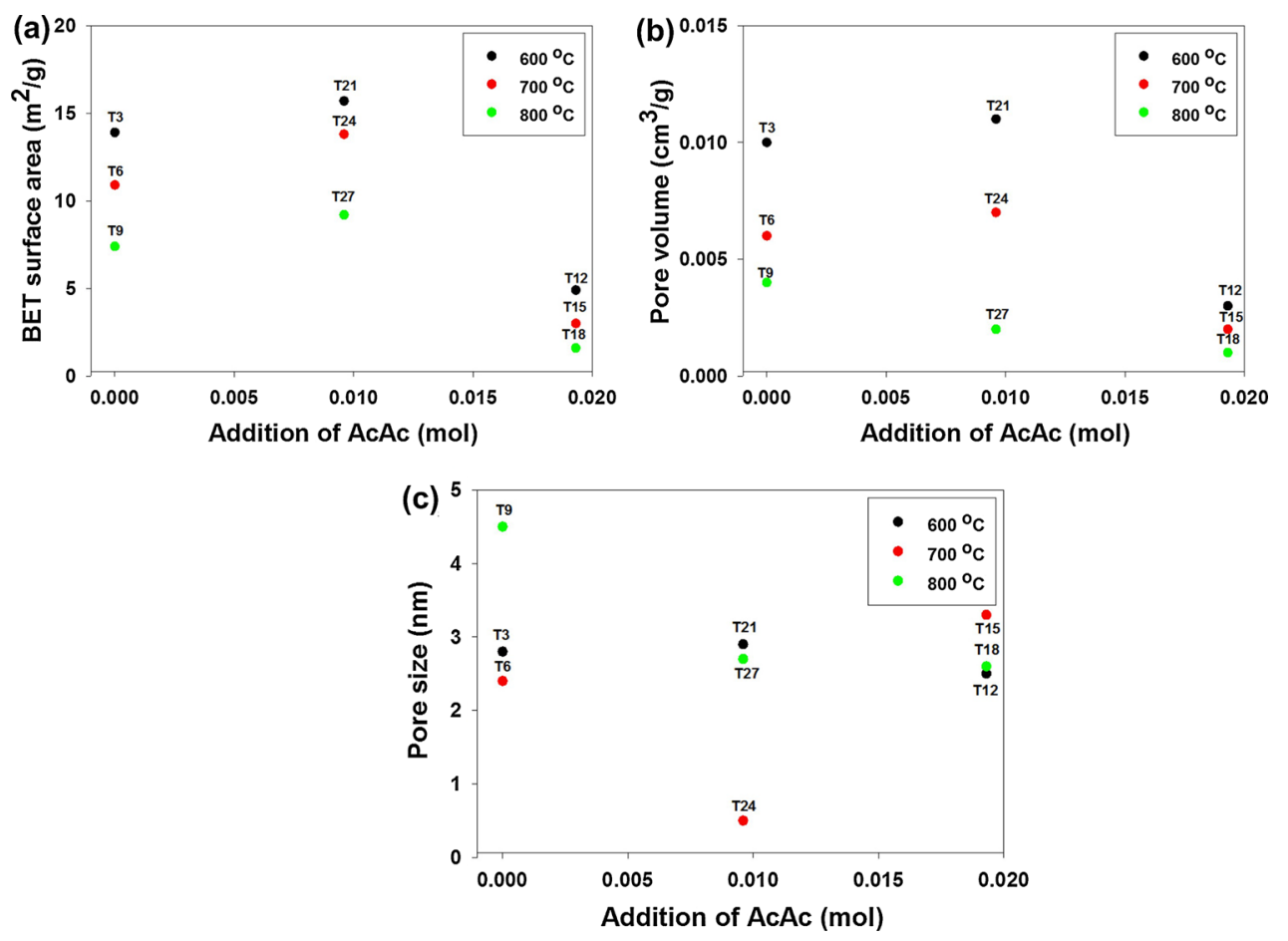

amount of $0.0096 \mathrm{~mol}$ at the titanium dioxide synthesis stage may be directly related to the dispersive nature of the materials obtained. These samples contained particles with smaller diameters than those of pure $\mathrm{TiO}_{2}$, this being directly linked to the porous structure parameters of the products of synthesis.

However, the addition of AcAc in an amount of 0.0193 mol causes significant deterioration in the porous structure parameters of the products. A considerable decrease in the BET surface area and pore volume relative to the pure $\mathrm{TiO}_{2}$ sample was observed for all samples obtained with the addition of chelating agent in an amount of
0.0193 mol. The addition of AcAc $(0.0193 \mathrm{~mol})$ also resulted in an increase in the mean size of pores relative to those of native $\mathrm{TiO}_{2}$. It was also observed that the BET surface area decreased with increasing temperature of the calcination process.

Addition of the chelating agent during the preparation of $\mathrm{TiO}_{2}$ caused significant changes in the porous structure parameters of the resulting samples. The results of BET analysis of the samples confirmed that by selecting an appropriate quantity of modifier (acetylacetone), it is possible to control the porous structure of the product. 
In contrast to the results of dispersive characteristics, determination of the porous structure parameters confirmed the surface area increase with the corresponding increase in the amount of primary particles in prepared $\mathrm{TiO}_{2}$ samples.

\subsection{Thermal analysis}

The thermal stability of selected samples was estimated using TGA/DTA analysis. On the basis of this analysis, thermograms were obtained showing thermogravimetric (TGA) and differential thermal analysis (DTA) curves, indicating physical and/or chemical changes that occur in a sample's structure during heat treatment.

The results of TGA of $\mathrm{TiO}_{2}$ samples (before calcination process), prepared with various amounts of catalyst and AcAc addition, are shown in Fig. 9. All TGA/DTA curves show endothermic peaks and the sample weight loss up to $130{ }^{\circ} \mathrm{C}$, which are attributed to the removal of physically adsorbed water. The exothermic peak at $270{ }^{\circ} \mathrm{C}$ and a broad one at $300-400{ }^{\circ} \mathrm{C}$ are related to decomposition of organic compounds, residual hydroxyl groups and AcAc ligands. Additionally, the exothermic peak observed at $390{ }^{\circ} \mathrm{C}$ correlates with the crystallization of the amorphous phase into the anatase. For sample obtained with chelating agent addition, this peak appears at $395^{\circ} \mathrm{C}$, different as in the case of $\mathrm{TiO}_{2}$ powder prepared without $\mathrm{AcAc}\left(310^{\circ} \mathrm{C}\right)$, which is in agreement with [43]. It can be assumed that above $400{ }^{\circ} \mathrm{C}$ the powder completely transforms into crystalline form, which is confirmed by weight stabilization. Moreover, presented TGA curves show two different steps of samples degradation-first in the range of $80-120^{\circ} \mathrm{C}$ related to free water loss and second in the range of $120-400{ }^{\circ} \mathrm{C}$ related to the following sample decomposition.

Figure 10a shows thermograms of titanium dioxide systems obtained without the chelating agent and calcined at different temperatures $\left(600,700\right.$ and $\left.800{ }^{\circ} \mathrm{C}\right)$. The resulting systems were analyzed to determine their thermal stability. In all of the systems, the main mass loss is observed within a temperature range of $30-600{ }^{\circ} \mathrm{C}$, corresponding to the loss of physically and chemically bound water. At this point, the mass loss is slightly above $0.7,0.6$ and $0.9 \%$, respectively, for samples T3, T6 and T9 and is almost equal to the total mass loss $(\sim 0.9,0.7$ and $\sim 1.2 \%$ for T3, T6 and T9, respectively). There was also noted a small exothermic effect associated with the transformation of the anatase form to the rutile form of titanium dioxide. DTA analysis of the $\mathrm{TiO}_{2}$ samples calcined at different temperatures shows exothermic peaks in a temperature range of $100-600{ }^{\circ} \mathrm{C}$, which also corresponds to crystallization of the amorphous phase into the anatase or rutile phase.

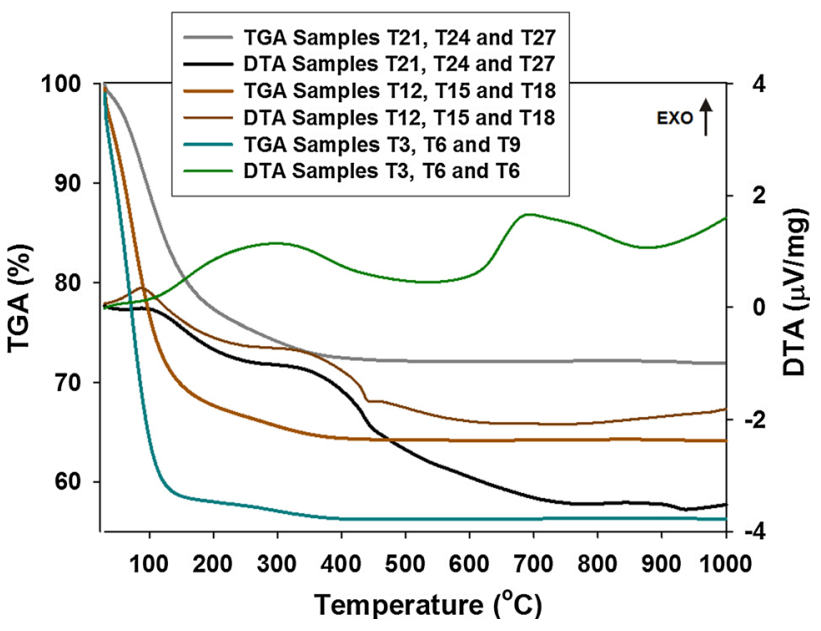

Fig. 9 TGA/DTA curves of titanium dioxide samples obtained with and without AcAc addition before calcination process

However, analysis of the TGA curves for the samples obtained with the addition of AcAc and calcined at $600{ }^{\circ} \mathrm{C}$ (Fig. 10b) shows the major weight loss of about $0.5-0.8 \%$ to occur in the temperature range $30-600{ }^{\circ} \mathrm{C}$. This weight loss is mainly associated with the local elimination of water bonded with the surface of the sample. In the temperature range $600-1000{ }^{\circ} \mathrm{C}$, the TGA curves show an additional weight loss of about 0.7 and $1.0 \%$ for T12 and T21, respectively, as a result of titania phase transformation as well as decomposition of the chelating agent.

\subsection{FT-IR analysis}

In order to identify the functional groups present on the surface of the $\mathrm{TiO}_{2}$ prepared by the sol-gel method, with or without chelating agent, selected samples were subjected to FT-IR analysis.

Figure 11 shows the FT-IR spectra of samples obtained with and without AcAc (samples T3, T12 and T21) and calcined at $600{ }^{\circ} \mathrm{C}$. The broad absorption peaks around $800-500 \mathrm{~cm}^{-1}$ are characteristic of a Ti-O-Ti network. The broad absorption peaks at approximately $3400 \mathrm{~cm}^{-1}$ are ascribed to the stretching vibrations of $\mathrm{O}-\mathrm{H}$ bonds indirectly related to water physically adsorbed on the surface. The band at $1430 \mathrm{~cm}^{-1}$ is associated with symmetric vibrations of the carboxyl $(\mathrm{C}-\mathrm{O})$ group. Analysis of the FT-IR spectra of the samples obtained with AcAc and calcined at $600{ }^{\circ} \mathrm{C}$ reveals a few peaks characteristic of the chelating agent. The FT-IR spectra do not show any characteristic absorption peaks for free acetylacetone at around 1707 and $1726 \mathrm{~cm}^{-1}$ due to the stretching $\mathrm{C}-\mathrm{C}$ and $\mathrm{C}-\mathrm{O}$ vibrations which are assigned of keto tautomeric $\mathrm{C}-\mathrm{O}$ group. When AcAc reacted completely with TTIP, the FTIR spectra showed a sharp absorption peak at $1580 \mathrm{~cm}^{-1}$, 
Fig. 10 TGA/DTA curves of titanium dioxide obtained: a without chelating agent and calcined at different temperature and $\mathbf{b}$ with AcAc and calcined at $600{ }^{\circ} \mathrm{C}$
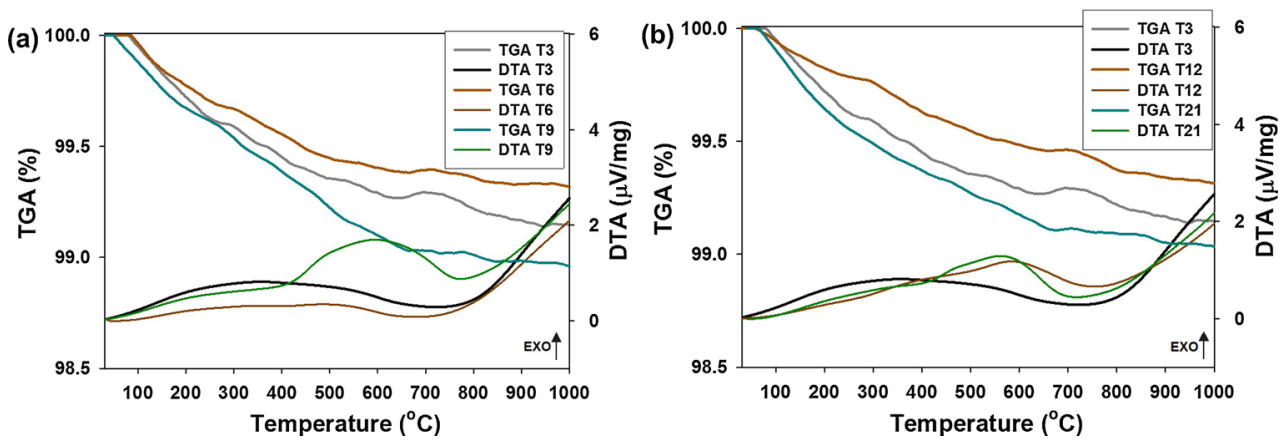

rising from the split of enol form of $\mathrm{C}-\mathrm{O}$ at $1630 \mathrm{~cm}^{-1}$. This proves the chelation occurring between AcAc and TTIP $[47,50]$. A peak was observed at about $1360 \mathrm{~cm}^{-1}$, which was one of the characteristics of $\mathrm{C}-\mathrm{O}$ deformation (for samples T12 and T21).

\subsection{Photocatalytic activity}

Figure 12 shows the photocatalytic degradation of C.I. Basic Blue 9 by UV irradiation in the presence of $\mathrm{TiO}_{2}$ prepared by the sol-gel method with or without chelating agent.

The efficiency of C.I. Basic Blue 9 photodegradation in the presence of the obtained samples was measured with reference to A11 commercial titanium dioxide (Chemical Works Police SA). Moreover, the decolorization of C.I. Basic Blue 9 under UV irradiation was performed, with $25 \%$ degradation efficiency, which corresponded to the literature [51]. The measurements showed the commercial anatase titanium dioxide (A11) to have very good photooxidation activity (the efficiency of its degradation of C.I. Basic Blue 9 was $97 \%$ ). The $\mathrm{TiO}_{2}$ samples obtained without AcAc and calcined at temperatures in the range

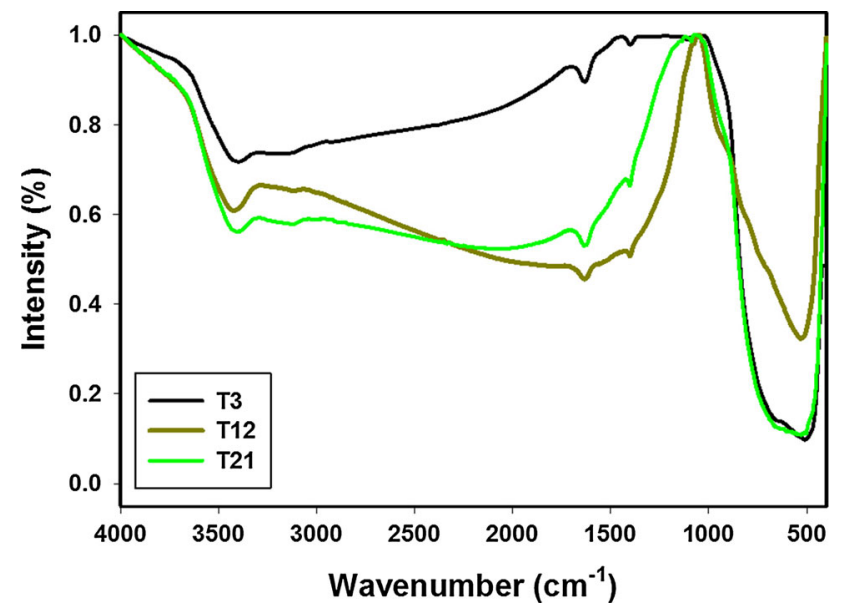

Fig. 11 FT-IR spectra of titanium dioxide obtained with and without AcAc and calcined at $600{ }^{\circ} \mathrm{C}$
600-800 ${ }^{\circ} \mathrm{C}$ (samples T3, T6 and T9) show higher photocatalytic activity in the decomposition of C.I. Basic Blue 9. The highest efficiency of C.I. Basic Blue 9 degradation (over $98.3 \%$ ) was observed in the presence of $\mathrm{TiO}_{2}$ obtained without AcAc and calcined at $800{ }^{\circ} \mathrm{C}$ (sample T9). Moreover, it was observed that photocatalytic activity increases with increasing temperature of calcination of titanium dioxide. This confirms certain literature reports stating that a mixture of rutile and anatase has better photocatalytic properties than pure anatase [52, 53].

The $\mathrm{TiO}_{2}$ samples obtained with the addition of chelating agent and calcined at temperatures of $600-800{ }^{\circ} \mathrm{C}$ (samples $\mathrm{T} 21, \mathrm{~T} 24$ and T27) show lower activity in the photocatalytic decomposition of C.I. Basic Blue 9. The degradation efficiency was $95.9 \%$ in the presence of sample T21 and slightly lower ( 93.8 and $89.0 \%$ ) in the case of photocatalysis using samples T24 and T27.

\section{Discussion}

The alkoxides are very air-sensitive and rapidly precipitate with moisture, leading to the component segregation and agglomeration of large-sized complex hydroxide particles;

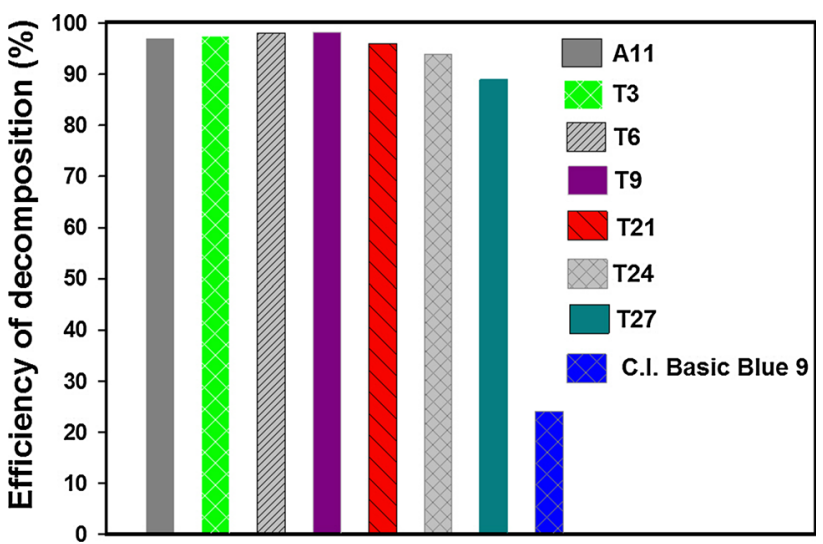

Fig. 12 Efficiency of C.I. Basic Blue 9 photodegradation in the presence of synthesised $\mathrm{TiO}_{2}$ samples 
hence, adding a chelating agent such as binary alcohol or organic acids to the alkoxide solution is an effective way to control the rate of hydrolysis. Several literature reports have confirmed the influence of different modified alkoxide precursors on the physicochemical properties of the resulting titania.

Attar et al. [43] reported the effect of modifier ligands such as acetylacetone and acetic acid on the formation of titanium dioxide via the sol-gel method. The authors studied the influence of chelating agent on the morphology, thermal stability and crystalline structure of the resulting titania. The SEM images of titania prepared without chelating ligands show that some particles are non-spherical and highly agglomerated. Morphological analysis of samples obtained in the presence of chelating agent shows that the addition of complex ligands leads to products with particles of smaller diameter (about 20-25 nm for AcAc and 25-30 nm following the addition of acetic acid) compared with native $\mathrm{TiO}_{2}$. Samples prepared with chelating agent are characterized by particles of spherical shape. The type of chelating agent was found to play an important role in the thermal stability. Titanium dioxide prepared with acetylacetone or without chelating agent showed higher weight loss (22 and $17 \%$, respectively) than that synthesized with acetic acid (15\%). Titanium dioxide obtained without chelating agent is crystalline after calcination at $300{ }^{\circ} \mathrm{C}$, in contrast to samples prepared with acetylacetone and acetic acid, which prevent the crystallization of titania at temperatures below $400{ }^{\circ} \mathrm{C}$. XRD analysis showed that the presence of chelating agent caused an increase in the temperature of transition of the amorphous phase to anatase.

You et al. [44] studied the influence of the amount of acetylacetone (from 0 to $1 \mathrm{~mL}$ ) and the reaction time (from 2 to $32 \mathrm{~h}$ ) on the morphology and particle size, surface area, chemical composition, crystalline structure and thermal stability of $\mathrm{TiO}_{2}$ prepared by a single-step swelling process of a polystyrene template. They noted that the amount of AcAc and the reaction time affect the physicochemical properties of the synthesized materials. The particle size of the $\mathrm{TiO}_{2} / \mathrm{PS}$ composite before the polymer was removed was larger than the particle size after calcination. Dispersive analysis showed an apparent upward trend in the diameter of particles as the amount of AcAc and reaction time increased. The titanium dioxide particles were spherical with a diameter of $450 \mathrm{~nm}$ when the amount of chelating agent approached $0.1 \mathrm{~mL}$ and the reaction time reached $8 \mathrm{~h}$. The results of BET analysis showed that titanium dioxide with large BET surface area and pore volume was obtained as the reaction time and quantity of chelating agent increased.

Chang et al. [46] obtained titania nanocrystals from aqueous solutions of peroxo titanium complex starting from titanium tetraisopropoxide (TTIP), acetic acid and hydrogen peroxide in water/propan-2-ol media by a facile sol-gel process. A study was made of the influence of $\mathrm{pH}$ on the morphology and crystalline structure of titania obtained by the sol-gel method in the presence of acetic acid as chelating agent. It was found that the presence of chelating agent $(\mathrm{AcOH})$ or ligands $\left(\mathrm{H}_{2} \mathrm{O}_{2}\right)$ and their sequence of addition have a considerable influence on the phase formation and morphology of $\mathrm{TiO}_{2}$. The authors noted that the $\mathrm{pH}$ of the solution critically determines the composition of the hydrolyzed product, which in turn influences the titania phase type. The addition of AcOH/TTIP or TTIP/AcOH solution (with $\mathrm{pH}$ in the range 3.9-4.1) to water or vice versa gave a solution in the $\mathrm{pH}$ range $3.2-3.5$, which is favorable for anatase nucleation. When TTIP was introduced to $\mathrm{H}_{2} \mathrm{O}_{2}$ solution, the $\mathrm{pH}$ changed from $3.4-3.5$ to 1.1 , and nucleation of both anatase and rutile was observed in the same proportions. The addition of TTIP/AcOH to $\mathrm{H}_{2} \mathrm{O}_{2}$ solution caused the $\mathrm{pH}$ to drop from 3.9-4.1 to 1.5 , rather slowly, leading to predominantly anatase $(92 \%)$ with traces of rutile.

Huang et al. [45] obtained titanium dioxide via a hydrothermal method, using titanium tetrabutoxide as the source material and acetylacetone as the chelating agent. They studied the influence of the chelating agent on the crystalline structure and morphology of the resulting $\mathrm{TiO}_{2}$. The titanium dioxide obtained with the addition of chelating agent had particles with diameters ranging from several nanometers to $20 \mathrm{~nm}$. The authors noted that particle size and average crystallite size decreased gradually when the molar ratio of $\mathrm{AcAc} / \mathrm{Ti}$ was increased to 0.2 , and after that, they increased slightly up to a molar ratio of 0.4 .

Choi et al. [54] synthesized thin films and membranes of $\mathrm{TiO}_{2}$ with enhanced catalytic activity and better structural properties using a novel simple sol-gel route, employing acetic acid and Tween ${ }^{\circledR} 80$ as surfactant. The resulting titania had high surface area $\left(147 \mathrm{~m}^{2} / \mathrm{g}\right)$ and high porosity (46 \%), a narrow pore size distribution ranging from 2 to $8 \mathrm{~nm}$, homogeneity without cracks and pinholes, as well as enhanced catalytic properties such as active anatase phase, and small crystallite size $(9 \mathrm{~nm})$. The synthesized $\mathrm{TiO}_{2}$ photocatalysts were highly efficient for the destruction of C.I. Basic Blue 9 and creatinine in water. The prepared photocatalytic $\mathrm{TiO}_{2} /$ $\mathrm{Al}_{2} \mathrm{O}_{3}$ composite membranes exhibited high water permeability and effective organic retention. The proposed modified sol-gel method was useful for the preparation of nanostructured $\mathrm{TiO}_{2}$ films and membranes with high photocatalytic activity and desired pore structure, as well as for the synthesis of similar crystal nanostructures of other oxide materials for applications in catalysis and separation.

\section{Conclusions}

The results of the dispersive analysis presented above show that an increase in the amount of catalyst used in the process of obtaining titanium dioxide via the sol-gel method 
leads to an increase in the degree of nucleation and hydrolysis, resulting in an increase in particle diameter and a significant tendency for the particles to agglomerate. Moreover, in the case of titania obtained with the addition of chelating agent, the diameter of particles tended to decrease with a decreasing quantity of AcAc. The presence of chelating agent in the synthesis of titanium dioxide decreases the rate of hydrolysis and results in the formation of particles with smaller diameter.

The XRD analysis shows that, in the preparation of titanium dioxide without addition of chelating agent (AcAc), the contribution of the rutile structure increases with increasing temperature of calcination. Moreover, XRD analysis showed that, by selecting a suitable amount of chelating agent (AcAc) at the stage of titanium dioxide synthesis, followed by thermal processing, it is possible to control its crystalline structure, causing a decrease in the temperature of transformation of anatase to rutile.

The addition of chelating agent in the process of $\mathrm{TiO}_{2}$ preparation caused significant changes in the porous structure parameters of the resulting samples. Analysis of the porous structure of $\mathrm{TiO}_{2}$ obtained via the proposed method (with the addition of AcAc in an amount of $0.0096 \mathrm{~mol}$ ) showed these powders to have a higher surface area than native titania. A considerable decrease in the BET surface area and pore volume relative to that of the pure $\mathrm{TiO}_{2}$ sample was observed for all samples obtained with the addition of chelating agent in an amount of $0.0193 \mathrm{~mol}$.

The FT-IR analysis confirmed the formation of a chelating bond between titanium alkoxide and acetylacetone.

The $\mathrm{TiO}_{2}$ systems prepared by the sol-gel method with or without the addition of chelating agent exhibit relatively high photocatalytic activity in the decomposition of C.I. Basic Blue 9. The results clearly indicate the possibility of carrying out degradation of this type of organic compound using powder materials prepared via the proposed method.

Acknowledgments This work was supported by Polish National Centre of Science research Grant No. 2011/01/B/ST8/03961.

Open Access This article is distributed under the terms of the Creative Commons Attribution 4.0 International License (http:// creativecommons.org/licenses/by/4.0/), which permits unrestricted use, distribution, and reproduction in any medium, provided you give appropriate credit to the original author(s) and the source, provide a link to the Creative Commons license, and indicate if changes were made.

\section{References}

1. Wypych G (1999) Handbook of fillers, 2nd edn. ChemTec Publishing, Toronto

2. Braun JH (1997) Titanium dioxide a review. J Coat Tech 69:59-72
3. Siwińska-Stefańska K, Krysztafkiewicz A, Ciesielczyk F, Paukszta D, Sójka-Ledakowicz J, Jesionowski T (2010) Physicochemical and structural properties of $\mathrm{TiO}_{2}$ precipitated in an emulsion system. Physicochem Probl Miner Process 44:231-244

4. Beydoun D, Amal R, Low G, Mcevoy S (1999) Role of nanoparticles in photocatalysis. J Nanopart Res 1:439-458

5. Blake DM, Maness PC, Huang Z, Wolfrum EJ, Huang J, Jacoby WA (1999) Application of the photocatalytic chemistry of titanium dioxide to disinfection and the killing of cancer cells. Sep Purif Methods 28:1-50

6. Mozia S, Bubacz K, Janus M, Morawski AW (2012) Decomposition of 3-chlorophenol on nitrogen modified $\mathrm{TiO}_{2}$ photocatalysts. J Hazard Mater 203-204:128-136

7. Dolat D, Mozia S, Ohtani B, Morawski AW (2013) Nitrogen, iron-single modified $\left(\mathrm{N}-\mathrm{TiO}_{2}, \mathrm{Fe}-\mathrm{TiO}_{2}\right)$ and co-modified $(\mathrm{Fe}, \mathrm{N}-$ $\mathrm{TiO}_{2}$ ) rutile titanium dioxide as visible-light active photocatalysts. Chem Eng J 225:358-364

8. Sthathatos E, Tsiourvas D, Lianos P (1999) Titanium dioxide films made from reverse micelles and their use for the photocatalytic degradation of adsorbed dyes. Colloid Surf A 149:49-56

9. Comparelli R, Fanizza E, Curri ML, Cozzoli PD, Mascolo G, Passino R, Agostiano A (2005) Photocatalytic degradation of azo dyes by organic-capped anatase $\mathrm{TiO}_{2}$ nanocrystals immobilized onto substrates. Appl Catal B-Environ 55:81-91

10. Hadjiivanov KI, Klissurski DG (1996) Surface chemistry of titania (anatase) and titania-supported catalysts. Chem Soc Rev 25:61-69

11. Scolan A, Sanchez C (1998) Synthesis and characterization of surface-protected nanocrystalline titania particles. Chem Mater 10:3217-3223

12. Lal M, Chhabra V, Ayyub P, Maitra A (1998) Preparation and characterization of ultrafine $\mathrm{TiO}_{2}$ particles in reverse micelles by hydrolysis of titanium di-ethylhexyl sulfosuccinate. J Mater Res 13:1249-1254

13. Su C, Hong B-Y, Tseng C-M (2004) Sol-gel preparation and photocatalysis of titanium dioxide. Catal Today 96:119-126

14. Yang P, Lu C, Hua N, Du Y (2002) Titanium dioxide nanoparticles co-doped with $\mathrm{Fe}^{3+}$ and $\mathrm{Eu}^{3+}$ ions for photocatalysis. Mater Lett 57:794-801

15. Bessekhouad Y, Robert D, Weber JV (2003) Synthesis of photocatalytic $\mathrm{TiO}_{2}$ nanoparticles: optimization of the preparation conditions. J Photochem Photobiol A 157:47-53

16. Kormann C, Bahnemann DW, Hoffmann R (1988) Preparation and characterization of quantum-size titanium dioxide. J Phys Chem 92:5196-5201

17. Li B, Wang X, Yan M, Li L (2002) Preparation and characterization of nano- $\mathrm{TiO}_{2}$ powder. Mater Chem Phys 78:184-188

18. Kim C-S, Moon BK, Park J-H, Chung ST, Son S-M (2003) Synthesis of nanocrystalline $\mathrm{TiO}_{2}$ in toluene by a solvothermal route. J Cryst Growth 254:405-410

19. Wang C, Deng Z-X, Zhang G, Fan S, Li Y (2002) Synthesis of nanocrystalline $\mathrm{TiO}_{2}$ in alcohols. Powder Technol 125:39-44

20. Kang M, Kim B-J, Cho SM, Chung C-H, Kim B-W, Han GY, Yoon KJ (2002) Decomposition of toluene using an atmospheric pressure plasma $/ \mathrm{TiO}_{2}$ catalytic system. J Mol Catal A-Chem 180:125-132

21. Kominami H, Kohno M, Takada Y, Inoue M, Inui T, Kera Y (1999) Hydrolysis of titanium alkoxide in organic solvent at high temperatures: a new synthetic method for nanosized, thermally stable titanium(IV) oxide. Ind Eng Chem Res 38:3925-3931

22. Kolen'ko YV, Burukhin AA, Churagulov BR, Oleynikov NN (2003) Synthesis of nanocrystalline $\mathrm{TiO}_{2}$ powders from aqueous $\mathrm{TiOSO}_{4}$ solutions under hydrothermal conditions. Mater Lett 57:1124-1129

23. Milea CA, Bogatu C, Duţă A (2011) The influence of parameters in silica sol-gel process. Bull Transilv Univ Braş Ser I Eng Sci $4: 59-66$ 
24. Brinker CJ, Scherer GW (1990) Sol-Gel science: the physics and chemistry of sol-gel processing. Academic Press, Boston

25. Chan Y-L, Pung S-Y, Sreekantan S (2013) Degradation of organic dye using $\mathrm{ZnO}$ nanorods based continuous flow water purifier. J Sol-Gel Sci Technol 66:399-405

26. Wu L-A, Jiang X, Wu S, Yao R, Qiao X, Fan X (2014) Synthesis of monolithic zirconia with macroporous bicontinuous structure via epoxide-driven sol-gel process accompanied by phase separation. J Sol-Gel Sci Technol 69:1-8

27. Ciesielczyk F, Przybysz M, Zdarta J, Piasecki A, Paukszta D, Jesionowski T (2014) The sol-gel approach as a method of synthesis of $\mathrm{xMgO} \cdot \mathrm{ySiO} \mathrm{S}_{2}$ powder with defined physicochemical properties including crystalline structure. J Sol-Gel Sci Technol. doi:10.1007/s10971-014-3398-1

28. Vrancken KC, Possemiers K, Voort PVD, Vansant EF (1995) Surface modification of silica gels with aminoorganosilanes. Colloid Sur A 98:235-241

29. Mark JE, Lee CYC, Bianconi PA (1995) Hybrid organic-inorganic composites. American Chemical Society, Washington

30. Cerveau G, Corriu RJP, Lepeytre C, Mutin PH (1998) Influence of the nature of the organic precursor on the textural and chemical properties of silsesquioxane materials. J Mater Chem $12: 2707-2714$

31. Corriu R (1998) A new trend in metal-alkoxide chemistry: the elaboration of monophasic organic-inorganic hybrid materials. Polyhedron 17:925-934

32. Corriu RJP, Leclerq D (1996) Recent developments of molecular chemistry for sol-gel processes. Angew Chem Int Ed 35:1420-1436

33. Shea KJ, Loy DA, Webster O (1992) Arylsilsesquioxane gels and related materials. New hybrids of organic and inorganic networks. J Am Chem Soc 114:6700-6710

34. Jackson CL, Bauer BJ, Nakatami AI, Barnes J (1996) Synthesis of hybrid organic-inorganic materials from interpenetrating polymer network chemistry. Chem Mater 8:727-733

35. Nassar EJ, Ciuffi KJ, Ribeiro SJL, Messaddeq Y (2003) Europium incorporated in the silica matrix obtained by sol-gel: luminescent materials. Mat Res 6:557-562

36. Beari F, Brand M, Jenkner P, Lehnert R, Metternich HJ, Monkiewicz J, Siesler H (2001) Organofunctional alkoxysilanes in dilute aqueous solution: new accounts on the dynamic structural mutability. J Orgmomet Chem 625:208-216

37. Nassar EJ, Neri CR, Calefi PS, Serra OA (1999) Functionalized silica synthesized by sol-gel process. J Non-Cryst Solids 247:124-128

38. Stöber W, Fink A, Bohn E (1968) Controlled growth of monodisperse silica spheres in the micron size range. J Colloid Interface Sci 26:62-69

39. Papacídero AT, Rocha LA, Caetano BL, Molina EF, Sacco C, Nassar EJ, Martinelli Y, Mello C, Nakagaki S, Ciuffi KJ (2006) Preparation and characterization of spherical silica-porphyrin catalysts obtained by the sol-gel methodology. Colloid Surf A 275:27-35

40. Nassar EJ, Nassor ECO, Ávila LR, Pereira PFS, Cestari A, Luz LM, Ciuffi KJ, Calefi PS (2007) Spherical hybrid silica particles modified by methacrylate groups. J Sol-Gel Sci Technol 43:21-26

41. Ricci GP, Rocha ZN, Nakagaki S, Castro KADF, Crotti AEM, Calefi PS, Nassar EJ, Ciuffi KJ (2011) Iron-alumina materials prepared by the non-hydrolytic sol-gel route: synthesis, characterization and application in hydrocarbons oxidation using hydrogen peroxide as oxidant. Appl Catal A-Gen 389:147-154

42. Matos MG, Pereira PFS, Calefi PS, Ciuffi KJ, Nassar EJ (2009) Preparation of a $\mathrm{GdCaAl}_{3} \mathrm{O}_{7}$ matrix by the non-hydrolytic sol-gel route. J Lumin 129:1120-1124

43. Attar AS, Ghamsari MS, Hajiesmaeilbaigi F, Mirdamadi S (2008) Modifier ligands effects on the synthesized $\mathrm{TiO}_{2}$ nanocrystals. J Mater Sci 43:1723-1729

44. You JH, Hsu KY (2010) Influence of chelating agent and reaction time on the swelling process for preparation of porous $\mathrm{TiO}_{2}$ particles. J Eur Ceram Soc 30:1307-1315

45. Huang T, Huang W, Zhou C, Situ Y, Huang H (2012) Superhydrophilicity of $\mathrm{TiO}_{2} / \mathrm{SiO}_{2}$ thin films: synergistic effect of $\mathrm{SiO}_{2}$ and chase-separation-induced porous structure. Surf Coat Tech 213:126-132

46. Chang JA, Vithal M, Baek IC, Seok SI (2009) Morphological and phase evolution of $\mathrm{TiO}_{2}$ nanocrystals prepared from peroxo titanate complex aqueous solution: influence of acetic acid. J Solid State Chem 182:749-756

47. Zhou C, Ouyang J, Yang B (2013) Retarded hydrolysis condensing reactivity of tetra butyl titanate by acetylacetone and the application in dye sensitized solar cells. Mater Res Bull 48:4351-4356

48. Cullity BD (1978) Elements of X-ray diffraction. Addison Wesley Publishing Company Inc, Menlo Park

49. Zhang W, Chen S, Yu S, Yin Y (2007) Experimental and theoretical investigation of the $\mathrm{pH}$ effect on the titania phase transformation during the sol-gel process. J Cryst Growth 308:122-129

50. Chen H-J, Wang L, Chiu W-Y (2007) Chelation and solvent effect on the preparation of titania colloids. Mater Chem Phys 101:12-19

51. Djellabi R, Ghorab MF, Cerrato G, Morandi S, Gatto S, Oldani V, Di Michele A, Bianchi CL (2015) Photoactive $\mathrm{TiO}_{2}$-montmorillonite composite for degradation of organic dyes in water. J Photochem Photobiol A 295:57-63

52. Watson SS, Beydoun D, Scott JA, Amal R (2003) The effect of preparation method on the photoactivity of crystalline titanium dioxide particles. Chem Eng J 95:213-220

53. Mills A, Lee SK, Lepre A (2003) Photodecomposition of ozone sensitized by a film of titanium dioxide on glass. J Photochem Photobiol A 155:199-205

54. Choi H, Stathatos E, Dionysiou DD (2006) Sol-gel preparation of mesoporous photocatalytic $\mathrm{TiO}_{2}$ films and $\mathrm{TiO}_{2} / \mathrm{Al}_{2} \mathrm{O}_{3}$ composite membranes for environmental applications. Appl Catal B-Environ 63:60-67 